\title{
Management of HCV peri-transplant recapitulates management of CMV
}

An interesting recent paper from colleagues in the UK Blood and Transplant Research Unit on Organ Donation and Transplantation holds out the potential of reducing the number of people who die while waiting for an organ to become available.(1) Their proposal is that organs proven to be from donors with anti-HCV antibodies should be transplanted and that, if transmission of $\mathrm{HCV}$ from donor to recipient occurs, it should be managed by treating the recipient post-transplant with directly acting antiviral agents (DAA) active against HCV.(1)

Until now, many transplant centres have offered HCV positive donor organs to recipients who are also HCV positive with equivalent graft survival to HCV negative donor organs.(2) With the advent of DAA regimes for hepatitis $C$ that are highly effective and with a good safety profile, organs from HCV positive donors recently been used where the risk of dying while waiting for a kidney, liver or heart to become available exceeds the risk of acquiring chronic HCV infection.(3-6) The authors of the recent paper cite 76 such donations that led to 92 transplants.(1) In most cases, these organs were offered to recipients who were already infected with HCV and thus fully aware of the long term complications of HCV infection, including cirrhosis and primary hepatocellular carcinoma.(1) What is now proposed is that recipients uninfected with HCV should be offered HCV-positive organs on the understanding that virtually all of the cases of transmitted HCV will be treated effectively and safely with DAA. $(1,7)$ No serious drug-drug interactions with standard anti-rejection drug therapy are expected.

There is no doubt that the availability of DAA has revolutionised the treatment of chronic HCV. Early combinations of drugs had poor efficacy against some genotypes of HCV, but we now have several combinations that can treat all genotypes and achieve 99\% sustained virological response (SVR) after 12 weeks of treatment without the need for interferon or ribavirin.(5) These can be termed cures, because HCV requires ongoing replication in order to persist and does not have a reservoir in the body equivalent to latency in herpesviruses or the covalently closed circular DNA of hepatitis B virus. Even people with cirrhosis caused by HCV can have their liver dysfunction stabilised and reversed such that HCV has decreased dramatically as the primary indication for liver transplantation.(1) More evidence is needed on the success rate of treating HCV immediately post-transplant and a pilot study to address this in the UK is underway.(1) The SVR will be recorded at 12 weeks and again at 24 weeks. Although the DAA drugs are very expensive, the authors of the recent paper predict that this new approach will be cost effective.(1) When compared to the cost of ongoing renal dialysis, the initial costs of renal transplant alone are repaid within two years, a time that increases to 4 years when the additional costs of diagnosing and treating HCV are included.(1) To put that another way, the costs of treating with DAA are about the same as the costs of a renal transplant. 
The interim analysis of an open label study in heart transplant recipients has just been published. In this study, patients consented to receive HCV positive donor hearts. Twenty patients received transplants from viraemic donors and were treated with a pan genotypic regime, glecaprevir - pibrentasvir immediately before and for 8 weeks after the transplant.(8) All achieved a sustained viral response. Five patients received transplants from $\mathrm{HCV}$ antibody positive, RNA negative donors. These patients were monitored and none developed HCV viraemia. Patient and graft survival was $100 \%$ after median follow up 10.7 months, and importantly, the median waiting time from listing to transplant was short at 20 days.(8)

This new development means that virologists will have to stop considering the presence of anti-HCV antibodies in potential donors as a contraindication to transplantation. Indeed, as more and more people with HCV infection are detected and treated, increasing numbers of donors can be expected to have a past medical history of cured HCV.(1) Normally, a nucleic acid amplification test for HCV RNA would be done to confirm viraemia, but it is unlikely that time would be available for this to occur before transplant. Instead, this test on the donor should proceed and a positive result used as an indication for monitoring the recipient and treating with DAA if HCV RNA becomes detectable.(1)

Of course, we have been here before; what is being proposed is pre-emptive therapy for HCV as already practised for CMV.(9) The new HCV protocol will focus on a virus transmitted from the donor into an uninfected recipient $(D+R-$ combination). However, inevitably, the pilot study will also collate results from the same transplant centres where HCV positive recipients are treated posttransplant(5) after receiving an organ from a donor who is not infected with HCV (D-R+). Furthermore, detailed molecular studies will no doubt be performed on the $D+R+$ subset of patients to determine if recombination between different strains and genotypes of $\mathrm{HCV}$ is seen, recombination having been an important force in the evolution of CMV.(10-12) A major difference between HCV and CMV should be in the number of treatment courses required. It is expected that a single course of DAA will cure HCV post-transplant as it usually does in non-transplant patients. $(3,5)$ In contrast, once transmitted and treated, CMV can reactivate from latency to cause second or third episodes in individual patients. (9) It will also be interesting to see if the use of HCV-positive liver donors transmits a larger inoculum of virus to recipients than does the use of infected renal donors so that the risk of $\mathrm{HCV}$ transmission is increased in liver transplantation, compared to renal transplantation, as it is for CMV.(9) If so, a longer course of DAA than the standard 12 weeks may be required in liver transplant centres and serial monitoring of recipients for HCV RNA may be helpful to define this. Likewise, examining the nascent immune response of recipients to HCV may identify an immune correlate of protection which could inform the selection of antigens in experimental $\mathrm{HCV}$ vaccines as it has done for prototype CMV vaccines.(13)

In summary, this initiative is welcome and virologists will be enthusiastic collaborators with their transplant colleagues. If approximately 400 people die each year in the UK while awaiting organ availability, this new protocol has 
the potential to identify another 21 donors (providing 48 transplants) which equates to about $10 \%$ of the current 400 deaths.(1)

Paul Griffiths

Tanzina Haque

Aileen Marshall

1. Trotter PB, Summers DM, Ushiro-Lumb I, Robb M, Bradley JA, Powell $J$, et al. Use of Organs From Hepatitis C Virus-Positive Donors for Uninfected Recipients: A Potential Cost-Effective Approach to Save Lives?

Transplantation. 2018 Apr;102(4):664-72. PubMed PMID: 29166338.

2. Bowring MG, Kucirka LM, Massie AB, Ishaque T, Bae S, Shaffer AA, et al. Changes in Utilization and Discard of HCV Antibody-Positive Deceased Donor Kidneys in the Era of Direct-Acting Antiviral Therapy. Transplantation. 2018 Dec;102(12):2088-95. PubMed PMID: 29912046. Pubmed Central PMCID: 6249103.

3. Friebus-Kardash J, Gackler A, Kribben A, Witzke O, Wedemeyer H, Treckmann J, et al. Successful early sofosbuvir-based antiviral treatment after transplantation of kidneys from HCV-viremic donors into HCV-negative recipients. Transplant infectious disease : an official journal of the Transplantation Society. 2019 Jul 15:e13146. PubMed PMID: 31306562.

4. Reese PP, Abt PL, Blumberg EA, Van Deerlin VM, Bloom RD, Potluri VS, et al. Twelve-Month Outcomes After Transplant of Hepatitis C-Infected Kidneys Into Uninfected Recipients: A Single-Group Trial. Annals of internal medicine. 2018 Sep 4;169(5):273-81. PubMed PMID: 30083748.

5. Elfeki MA, Abou Mrad R, Modaresi Esfeh J, Zein NN, Eghtesad B, Zervos X, et al. Sofosbuvir/Ledipasvir Without Ribavirin Achieved High Sustained Virologic Response for Hepatitis C Recurrence After Liver Transplantation: Two-Center Experience. Transplantation. 2017 May;101(5):996-1000. PubMed PMID: 27631598.

6. McLean RC, Reese PP, Acker M, Atluri P, Bermudez C, Goldberg LR, et al. Transplanting hepatitis $C$ virus-infected hearts into uninfected recipients: A single-arm trial. American journal of transplantation : official journal of the American Society of Transplantation and the American Society of Transplant Surgeons. 2019 Sep;19(9):2533-42. PubMed PMID: 30768838.

7. Levitsky J, Formica RN, Bloom RD, Charlton M, Curry M, Friedewald J, et al. The American Society of Transplantation Consensus Conference on the Use of Hepatitis C Viremic Donors in Solid Organ Transplantation. American journal of transplantation : official journal of the American Society of Transplantation and the American Society of Transplant Surgeons. 2017 Nov;17(11):2790-802. PubMed PMID: 28556422.

8. Bethea ED, Gaj K, Gustafson JL, Axtell A, Lebeis T, Schoenike M, et al. Pre-emptive pangenotypic direct acting antiviral therapy in donor HCVpositive to recipient HCV-negative heart transplantation: an open-label study. The lancet Gastroenterology \& hepatology. 2019 Jul 25. PubMed PMID: 31353243. 
9. Atabani SF, Smith C, Atkinson C, Aldridge RW, Rodriguez-Peralvarez $\mathrm{M}$, Rolando N, et al. Cytomegalovirus replication kinetics in solid organ transplant recipients managed by preemptive therapy. AmJTransplant. 2012;12(9):2457-64.

10. Davison AJ, Dolan A, Akter P, Addison C, Dargan DJ, Alcendor DJ, et al. The human cytomegalovirus genome revisited: comparison with the chimpanzee cytomegalovirus genome. The Journal of general virology. 2003 Jan;84(Pt 1):17-28. PubMed PMID: 12533697.

11. Lassalle F, Daniel P. Depledge, Matthew B. Reeves, Amanda C. Brown, Mette T. Christiansen, Helena J. Tutill, Rachel J. Williams, Katja EinerJensen, Jolyon Holdstock, Claire Atkinson, Julianne R. Brown, Freek B. van Loenen, Duncan A. Clark, Paul D. Griffiths, Georges M.G.M. Verjans, Martin Schutten, Richard S.B. Milne, Francois Balloux, Judith Breuer. Islands of linkage in an ocean of pervasive recombination reveals two-speed evolution of human cytomegalovirus genomes. Virus evolution. 2016. Epub 21 June 2016.

12. Suarez NM, Wilkie GS, Hage E, Camiolo S, Holton M, Hughes J, et al. Human Cytomegalovirus Genomes Sequenced Directly From Clinical Material: Variation, Multiple-Strain Infection, Recombination, and Gene Loss. The Journal of infectious diseases. 2019 Jul 31;220(5):781-91. PubMed PMID: 31050742 . Pubmed Central PMCID: 6667795.

13. Baraniak I, Kropff B, McLean GR, Pichon S, Piras-Douce F, Milne RSB, et al. Epitope-Specific Humoral Responses to Human Cytomegalovirus Glycoprotein-B Vaccine with MF59: Anti-AD2 Levels Correlate with Protection from Viremia. The Journal of infectious diseases. 2018 Mar 8. PubMed PMID: 29528415. 